\title{
Involvement of Nuclear Accumulation of Heat Shock Protein 27 in Leptomycin B-Induced Apoptosis in HeLa Cells
}

\author{
Ayako Tsuchiya, Etsu Tashiro, Minoru Yoshida, Masaya Imoto
}

Received: October 29, 2005 / Accepted: December 5, 2005

(C) Japan Antibiotics Research Association

\begin{abstract}
Leptomycin B (LMB) is a Streptomyces metabolite that inhibits the chromosomal region maintenance (CRM)1-dependent nuclear export of proteins. It also induces apoptosis in several types of cancer cells, by a yet undefined mechanism. We used a functional proteomics approach to delineate the pathways and mediators involved in LMB-induced apoptosis in $\mathrm{HeLa}$ cells. Using two-dimensional gel electrophoresis, we searched for proteins accumulated in the nuclei of HeLa cells upon LMB treatment. Among such proteins we found prohibitin and Heat shock protein (Hsp)27, identified by peptide mass fingerprinting and mass spectrometry. Immunocytochemistry was carried out to confirm the LMB-induced nuclear accumulation of these two proteins in HeLa cells. Furthermore, we found that the cytoplasmic expression of Hsp27, but not prohibitin, partially inhibited LMB-induced apoptosis, indicating that nuclear sequestration of Hsp27 was, at least in part, involved in the apoptosis.
\end{abstract}

Keywords leptomycin B, apoptosis, Hsp27, chemical proteomics

\section{Introduction}

Leptomycin B (LMB), originally isolated from Streptomyces, possesses anti-tumor properties in vivo and in vitro [1 3]. It has been shown to induce apoptosis in several types of tumor cells, including HeLa cells $[4,5]$. However, the molecular mechanisms underlying LMB- induced apoptosis have not yet been elucidated. On the other hand, the cellular target of LMB has been identified as chromosomal region maintenance (CRM)1 [6]. CRM1 was found to be a nuclear export receptor, which mediates the nuclear-cytoplasmic transport of nuclear export signal (NES)-containing proteins or RNAs [7, 8]. Therefore, it is likely that proteins involved in the LMB-induced apoptosis become accumulated in the nucleus when the cells are treated with LMB.

Proteomics is a powerful tool developed to enhance the study of biological systems regulated by subcellular protein localization. This technique has been employed extensively to investigate the response of cells to drugs and diseases. However, to our knowledge, no proteomic study has been conducted to improve our understanding of the cellular response to LMB. Therefore, we first performed a comparative two-dimensional electrophoresis (2-DE) proteomic analysis of the nuclear proteins of untreatedand LMB-treated HeLa cells, and subsequently identified two differentially expressed proteins in the nuclei of LMB-treated HeLa cells by matrix-assisted laserdesorption ionization-time-of-flight mass spectrometry (MALDI-TOF-MS). Furthermore, we examined the effects of their cytoplasmic expression on LMB-induced apoptosis.

\section{Materials and Methods}

\section{Materials}

HeLa cells were cultured in DMEM containing $10 \%$ fetal bovine serum plus antibiotics.
M. Imoto (Corresponding author), A. Tsuchiya, E. Tashiro: Department of Biosciences and Informatics, Faculty of Science and Technology, Keio University, 3-14-1 Hiyoshi, Kohoku-ku, Yokohama 223-8522, Japan, E-mail: imoto@bio.keio.ac.jp
M. Yoshida: Chemical Genetics Laboratory, RIKEN, Wako, Saitama 351-0198, Japan 


\section{Flow Cytometry}

The cells were collected by trypsinization and combined with cells floating in the medium. The apoptotic cells were assessed by flow cytometric detection of sub-G1 DNA content after being stained with propidium iodide.

\section{Western Blot Analysis}

The cells were lysed with lysis buffer $(50 \mathrm{mM}$ Tris- $\mathrm{HCl}[\mathrm{pH}$ 7.4], $150 \mathrm{mM} \mathrm{NaCl}, 20 \mathrm{mM}$ EDTA and $0.5 \% \mathrm{NP}-40$ ) containing protease inhibitors. Then, $50 \mathrm{mg}$ of total cell lysate was separated by SDS-PAGE, transferred to a Hybond-P membrane (Amersham Biosciences, Tokyo, Japan), and probed with specific antibodies. This was followed by detection with the ECL Western blotting detection system (Perkin-Elmer Biosystems, Foster City, CA) and LAS-1000 (Fuji Film, Tokyo, Japan).

Primary antibodies included anti-prohibitin (II-14-10; NeoMarkers, Fremont, CA) and anti-Hsp27 (SPA-800; Stressgen, Victoria, BC Canada). The secondary antibodies were horseradish peroxidase-conjugated goat anti-mouse IgG (Amersham Biosciences).

\section{Immunofluorescence Microscopy}

HeLa cells were transfected with recombinant plasmids $(0.3 \mu \mathrm{g} /$ well $)$ in 12 -well plates using Lipofectamine ${ }^{\mathrm{TM}}$ Reagent (Invitrogen, Carlsbad, CA) according to the manufacturer's instructions. The cells were fixed with $3 \%$ paraformaldehyde, permeabilized with $0.5 \%$ Triton X-100 in PBS, and blocked in 3\% bovine serum albumin in PBS. For determining the distribution of endogenous prohibitin and Hsp27, the cells were stained with monoclonal primary antibodies and incubated with anti-mouse Alexa Fluor 488 (Invitrogen). At the same time, the nuclei were stained with TOPRO-3. Cells were observed using a laser-scanning confocal microscope system (Radiance 2000 : Bio-Rad).

\section{Preparation of Nuclear Extracts}

HeLa cells were homogenized with a syringe in buffer A (10 mM HEPES [pH 7.6], $25 \mathrm{mM} \mathrm{MgCl} 2,0.1 \%$ Triton X100, $1 \mathrm{mM}$ DTT and $1 \mathrm{mM}$ PMSF) and centrifuged for 10 minutes at $3.5 \mathrm{krpm}$. The resulting pellets rich in nuclei were resuspended in buffer A and layered on top of a $35 \%$ sucrose cushion in buffer A. The nuclei were pelleted for 30 minutes at $13 \mathrm{krpm}$ and reconstituted with lysis solution (8 M Urea, $2 \mathrm{M}$ thiourea, 2\% CHAPS, $1 \mathrm{mM}$ DTT and $0.5 \%$ IPG buffer).

\section{Two-dimensional Gel Electrophoresis}

For isoelectric focusing (IEF), $200 \mu \mathrm{g}$ of total protein was mixed in a rehydration buffer ( $8 \mathrm{M}$ urea, $2 \%$ Chaps, $100 \mathrm{mM}$ DTT, 0.5\% IPG Buffer and bromophenol blue) and loaded onto a 24-cm pH 3-10 Immobiline DryStrip (an IPG strip, Amersham biosciences). After rehydration of the IPG strip, IEF was carried out using a three-phase program: (i) $500 \mathrm{~V}, 1 \mathrm{Vh}$; (ii) $3500 \mathrm{~V}, 3 \mathrm{kVh}$ (gradient mode); (iii) $3500 \mathrm{~V}, 50 \mathrm{kVh}$. Prior to the second-dimensional electrophoresis, the IPG gel strips were incubated at room temperature for 15 minutes in an equilibration solution $(50 \mathrm{mM}$ Tris- $\mathrm{HCl}[\mathrm{pH} 8.8], 6 \mathrm{M}$ Urea, 2\% SDS and $30 \%$ glycerol) containing $1 \%$ DTT. This was followed by incubation for 15 minutes in the equilibration solution containing $2.5 \%$ iodoacetoamide. The gels were subsequently subjected to a second-dimensional run, using a Ettan DALT six on running SDS-PAGE gels (12.5\%). The 2-DE gels were stained with coomassie blue and scanned in a densitometer. Protein spots were quantified and numbered using ImageMaster Plutinum software. Protein levels with an increase of $>2$ fold over the untreated control after LMB treatment were considered to have changed substantially.

\section{In Gel Digestion}

Protein spots excised from the gel were destained in a 96well plate with acetonitrile and dried completely in a centrifugal evaporator. The dried gels were rehydrated on ice with a digestion buffer composed of $5 \mathrm{ng} / \mathrm{ml}$ of modified trypsin (Promege corp., Madison, WI). After the excess solution was removed, proteins were further digested at $37^{\circ} \mathrm{C}$ for 16 hours. The resultant peptides were extracted and concentrated using a centrifugal evaporator.

\section{MALDI-TOF MS and Database Search}

Peptide mixtures were applied to the sample target and airdried. After mixing it with the matrix (a-cyano-4hydroxycinnamic acid), the sample was analyzed in a Auto Flex MALDI-TOF MS spectrometer system (Bruker Daltonics Inc., Billerica, MA). The masses of peptides were measured as monoisotopic masses. To identify proteins, the monoisotopic masses were analyzed using the WWW search program Mascot with the NCBI or SWISSPROT database.

\section{Results}

\section{Leptomycin B Induced Apoptosis in HeLa Cells}

To examine the effect of LMB on apoptosis, we analyzed the amount of sub-G1 DNA, representing apoptosis, in HeLa cells treated with $1 \mathrm{ng} / \mathrm{ml}$ of LMB for 24 or 48 hours with a flow cytometer. Untreated HeLa cells showed a low basal level of apoptosis (2.2\%). LMB treatment for 24 hours resulted only in a small increase in the percentage of 


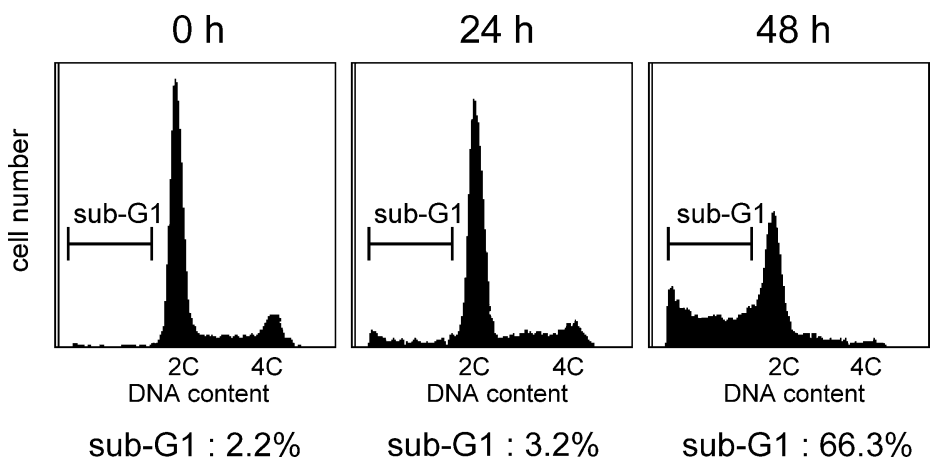

Fig. 1 LMB-induced apoptosis in HeLa cells.

HeLa cells were treated with $1 \mathrm{ng} / \mathrm{ml}$ of LMB for the periods indicated $(0,24$ and 48 hours) and the amount of sub-G1 DNA was analyzed with a flow cytometer. Apoptotic cells are denoted by the region sub-G1.

apoptotic cells (3.2\%), however, $66.3 \%$ of the cells underwent apoptosis after 48 hours treatment (Fig. 1).

As to the mechanism of LMB-induced apoptosis, we hypothesized that LMB inhibits the nuclear export of survival signaling molecules that become functional in the cytoplasm in normal cells, thereby inducing apoptosis. Therefore, we first tried to identify proteins whose nuclear expression levels increase upon treatment with LMB using 2-DE proteomics.

\section{Differential Proteomic Analysis of HeLa Cells with or Without LMB Treatment}

Nuclear protein extracts were prepared from HeLa cells that were treated with or without $1 \mathrm{ng} / \mathrm{ml}$ of LMB for 24 hours. To prove that the preparation of nuclei was 'clean' with minimal contamination from cytosolic components, each nuclear extract was analyzed by Western blotting (Fig. 2 insert). PARP was used as a marker for nuclei and tubulin for cytosol. Only a small amount of tubulin was present in the nuclear fraction, indicating that the fractionation experiments were carried out successfully.

Nuclear proteins thus obtained were separated using IPG strips $(\mathrm{pH}$ ranges $3 \sim 10$ ) by $2-\mathrm{DE}$ analysis to detect differences in expression between control and LMB-treated cells. Approximately 700 protein spots were detected in each 2-DE gels (Fig. 2). Comparing the 2-DE patterns of the untreated and LMB-treated cells, we picked spots that showed an increase in staining intensity with LMB treatment. These spots were excised from the gels, and the proteins were identified using MALDI-TOF MS. The peptide MS fingerprints obtained were used to search the NCBI and Swiss-Prot databases. Among proteins identified in the analysis were prohibitin and Hsp27, well-known apoptosis-related proteins. To confirm the result, the extent of the nuclear accumulation of these two proteins in response to LMB was examined by immuno-cytochemistry
(Fig. 3). In the absence of LMB, prohibitin and Hsp27 were mainly distributed in the cytoplasm, but a large portion of each protein was accumulated in the nucleus at 10 hours following LMB treatment. These results confirmed that prohibitin and Hsp27 were accumulated in the nucleus in response to LMB treatment in HeLa cells.

\section{Hsp27 Prevents LMB-induced Apoptosis}

Next we examined whether the nuclear sequestration of prohibitin or Hsp27 is associated with LMB-induced apoptosis in HeLa cells. For this purpose, $N$-terminally GFP-tagged prohibitin and Hsp27 constructs were generated, and HeLa cells were transiently transfected with each plasmid. Overexpressed GFP-prohibitin or GFPHsp27 was detected in the cytoplasm (Fig. 4a). Significant cytoplasmic expression of GFP-prohibitin or GFP-Hsp27 was observed even after LMB treatment. Moreover, in control GFP- or GFP-prohibitin-expressing HeLa cells, LMB induced a cell death that was accompanied by nuclear fragmentation, morphological modifications characteristic of apoptosis. In contrast, Hsp27 efficiently protected against LMB-induced cell death (Fig. 4a). Similarly, the flow cytometric analysis of DNA content demonstrated that treatment of control GFP-expressing HeLa cells with LMB caused a significant increase in the sub-G1 peak (61.1\%), and HeLa cells overexpressing prohibitin still underwent apoptosis upon LMB treatment (65.2\%). On the other hand, overexpression of Hsp27 inhibited apoptosis (38.3\%) induced by LMB (Fig. 4b). These results indicated that nuclear sequestration of Hsp27 is, at least in part, involved in the mechanism of LMB-induced apoptosis in HeLa cells.

\section{Discussion}

Although LMB has been reported to induce apoptosis in 
(a)

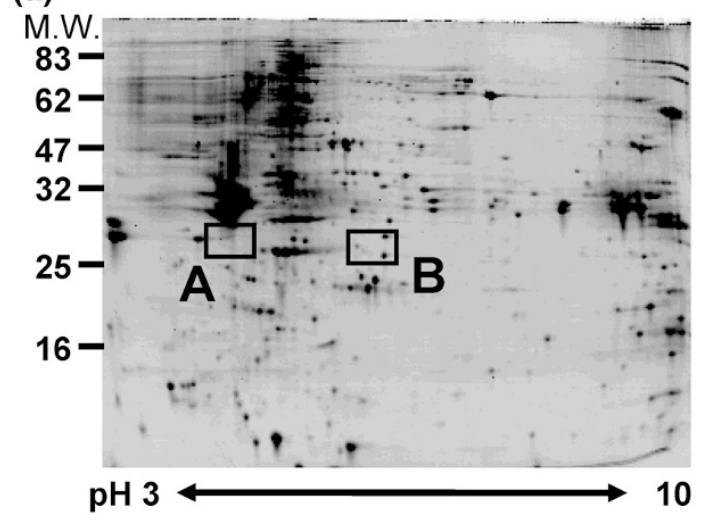

(b)

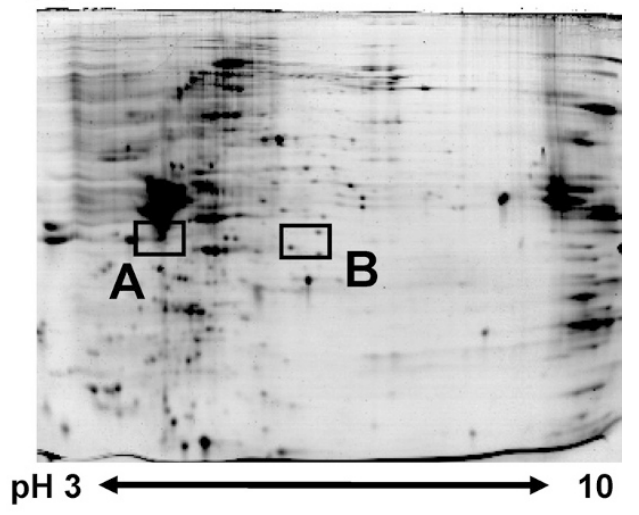

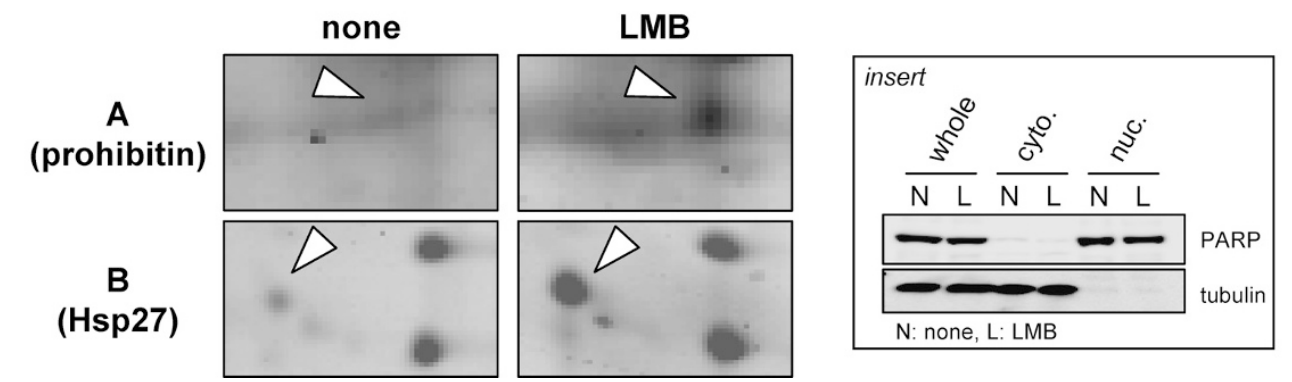

Fig. 2 2-DE map of nuclear extracts from HeLa cells.

(a) Control HeLa cells, untreated; (b) HeLa cells, treated with $1 \mathrm{ng} / \mathrm{ml}$ of LMB for 24 hours. Protein lysate (200 mg) was focused on a pH 3 10 IPG strip before being separated by a $12.5 \%$ polyacrylamide gel. The gels were coomassie-stained and compared protein spots that were differentially expressed in the nucleus with LMB treatment. The boxes delineate the regions containing spots that identified to be prohibitin (A) or Hsp27 (B). The respective spots are pointed with the arrows.

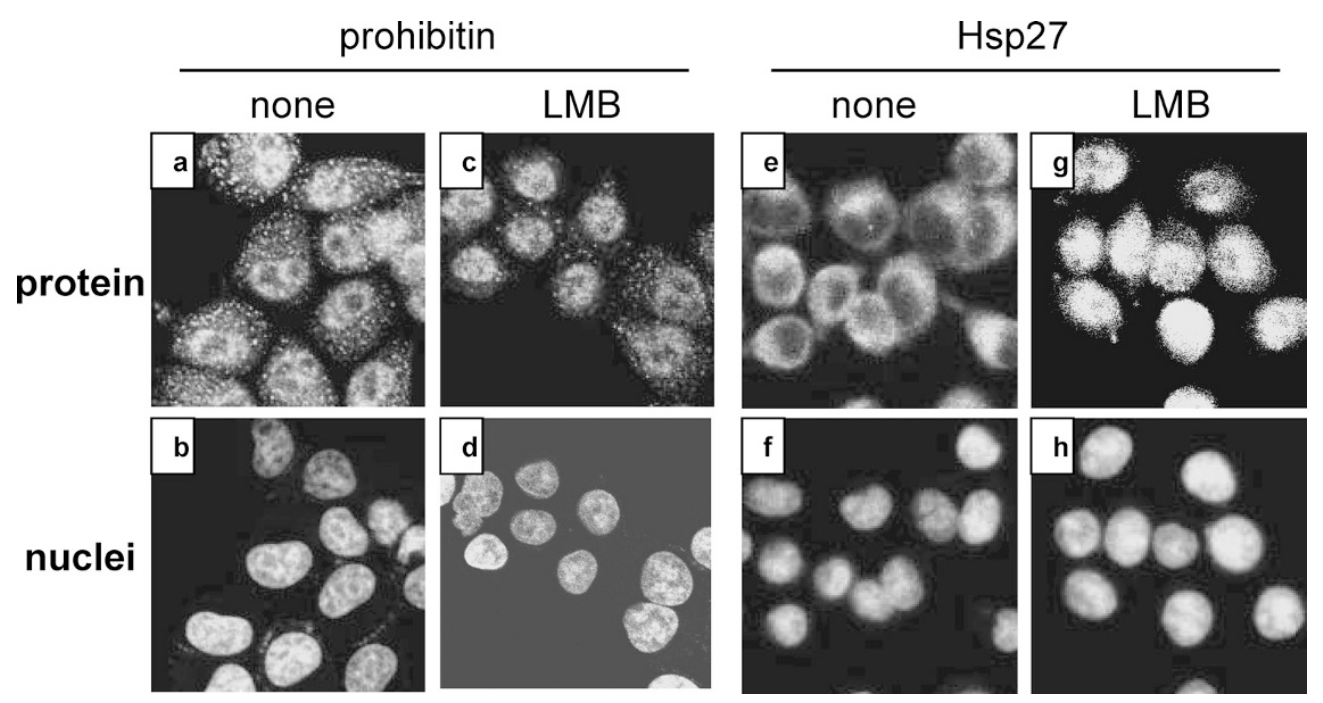

Fig. 3 LMB-induced nuclear accumulation of prohibitin and Hsp27 in HeLa cells.

Untreated HeLa cells or HeLa cells treated with $1 \mathrm{ng} / \mathrm{ml}$ of LMB for 10 hours were processed for indirect immunofluorescence with a monoclonal primary antibody against prohibitin $(a, c)$ or Hsp27 (e, g). Nuclei were stained with TOPRO-3 (b, d, f, h). Cells were observed with a laser-scanning confocal microscope system. 
(a)

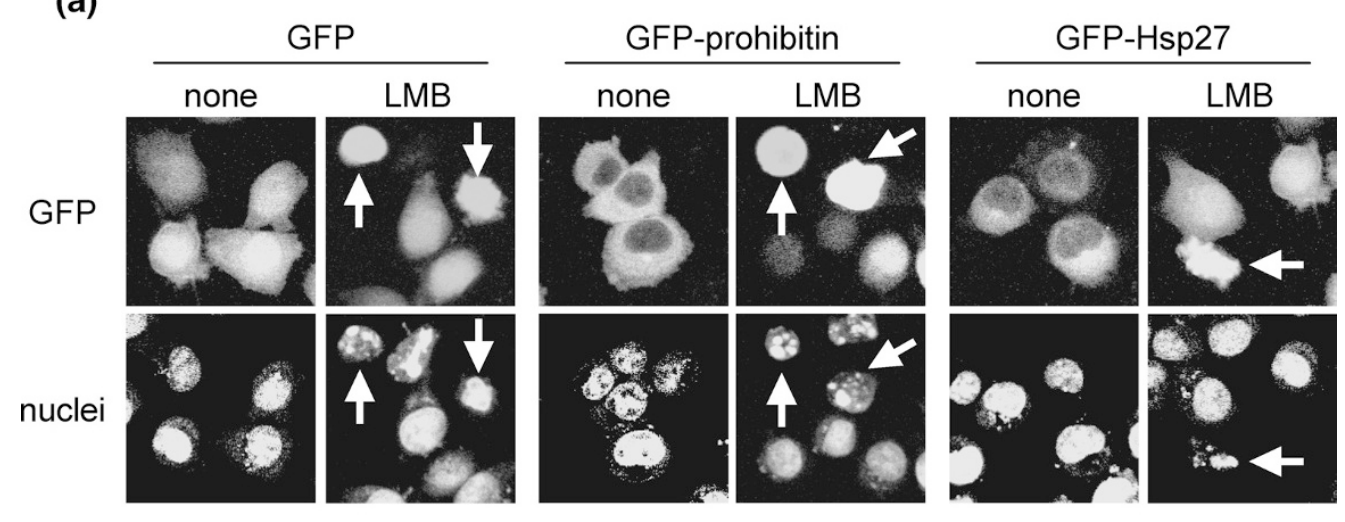

(b)

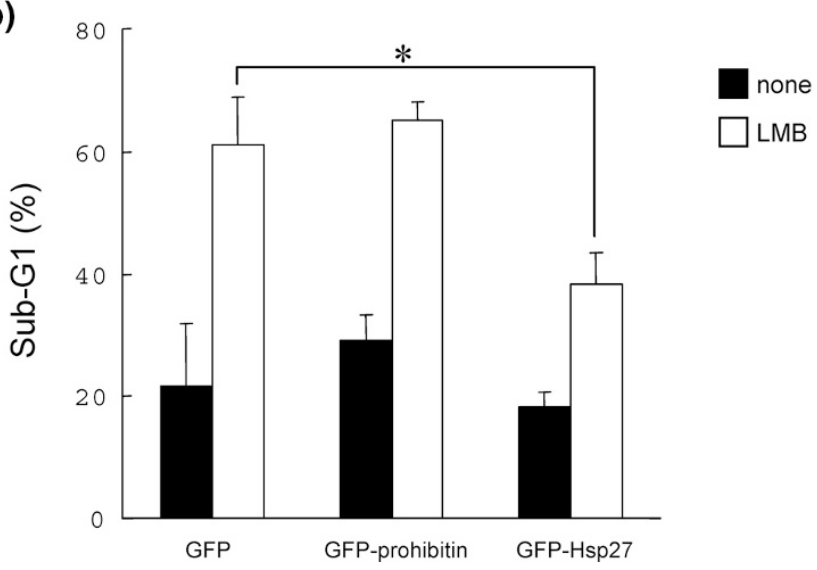

Fig. 4 Hsp27 protected HeLa cells from LMB-induced apoptosis.

HeLa cells were transfected with either pEGFP-prohibitin or pEGFP-Hsp27 using Lipofectamine. (a) After 3 hours, cells were treated with or without $1 \mathrm{ng} / \mathrm{ml}$ of LMB for 10 hours. Nuclei were stained with TOPRO-3. Cells were observed with a laser-scanning confocal microscope system. Arrows indicate apoptotic cells. (b) At 48 hours following LMB treatment, apoptotic cell numbers were determined by flow cytometer as described in materials and methods. Each column represents the average of values from three different experiments. ${ }^{*} p<0.05$ (Student's $t$ test).

several types of cancer cells, how it does so has not been fully elucidated. Because LMB is a specific inhibitor of nuclear export [6], it is possible that the proteins involved in LMB-induced apoptosis would be accumulated in the nucleus. In this study, we applied a comparative 2-DE technique to untreated and LMB-treated HeLa cells to screen for proteins accumulated in the nucleus on treatment with LMB, and found prohibitin and Hsp27 by MALDITOF-MS analysis. Although both of these proteins have a molecular weight of less than $40 \mathrm{kDa}$, the maximum for a protein to pass through the nuclear pore complex channel via passive diffusion, each is known to form a large complex $[9,10]$. Therefore, it is credible that their nuclear export is dependent on CRM-1, and can be inhibited by LMB.

Prohibitin, a potential tumor suppressor, is known to interact with several proteins such as p53, E2F and pRB and induce growth suppression [11 13]. In addition, prohibitin is reported to be found in the nucleus and mitochondria depending on the cell line $[14,15]$. Another function of prohibitin is to inhibit apoptosis, and this role is possibly related to its localization in the mitochondria [12, 16]. However, our results showed that overexpression of prohibitin did not prevent apoptosis induced by LMB, indicating that nuclear accumulation of prohibitin was not involved in the apoptosis.

Hsp27 belongs to a sub-family of stress proteins, which are detectable in virtually all organisms. We found that the cytoplasmic expression of Hsp27 partially inhibited LMBinduced apoptosis. Previous reports showed that Hsp27 exerts an anti-apoptotic effect in cells against heat shock and other injuries, which are mediated by chemotherapeutic drugs or oxidative stress [17 19] by counteracting procaspase 9 activation without altering cytochrome $c$ 
release [20]. This inhibition of procaspase 9 activation is possibly a consequence of the binding of Hsp27 to cytosolic cytochrome $c$, a phenomenon that subsequently down-regulates apoptosome formation [21]. The binding of Hsp27 to caspase 3 and its modulation has also been documented [22]. In HeLa cells, Hsp27 localized mainly in cytosol and only a small fraction of this protein colocalized with mitochondria. A 40\% decrease in the level of Hsp27, generated by antisense strategy, sensitized HeLa cells to staurosporine leading to cell death. This phenomenon correlated with a detection of cytochrome $c$ in the soluble cytoplasm and procaspase activation [23]. This leads to the conclusion that the cytosolic constitutive expression of Hsp27 in HeLa cells protects the cells from apoptosis. Therefore, it is conceivable that, when LMB induces nuclear sequestration, Hsp27 becomes unable to play a cytoprotective role in the cytoplasm or mitochondria, thereby allowing the cells to undergo apoptosis.

Acknowledgments This study was performed using Special Coordination Funds for Promoting Science and Technology from the Ministry of Education, Culture, Sports, Science and Technology, the Japanese Government.

\section{References}

1. Hamamoto T, Gunji S, Tsuji H, Beppu T. Leptomycins A and $\mathrm{B}$, new antifungal antibiotics. I. Taxonomy of the producing strain and their fermentation, purification and characterization. J Antibiot 36: 639-645 (1983)

2. Hamamoto T, Seto H, Beppu T. Leptomycins A and B, new antifungal antibiotics. II. Structure elucidation. J Antibiot 36: 646-650 (1983)

3. Hamamoto T, Uozumi T, Beppu T. Leptomycins A and B, new antifungal antibiotics. III. Mode of action of leptomycin B on Schizosaccharomyces pombe. J Antibiot 38: 1573-1580 (1985)

4. Jang BC, Paik JH, Jeong HY, Oh HJ, Park JW, Kwon TK, Song DK, Park JG, Kim SP, Bae JH, Mun KC, Suh MH, Yoshida M, Suh SI. Leptomycin B-induced apoptosis is mediated through caspase activation and down-regulation of Mcl-1 and XIAP expression, but not through the generation of ROS in U937 leukemia cells. Biochem Pharmacol 68: 263-274 (2004)

5. Lecane PS, Kiviharju TM, Sellers RG, Peehl DM. Leptomycin B stabilizes and activates p53 in primary prostatic epithelial cells and induces apoptosis in the LNCaP cell line. Prostate 54: 258-267 (2003)

6. Kudo N, Matsumori N, Taoka H, Fujiwara D, Schreiner EP, Wolff B, Yoshida M, Horinouchi S. Leptomycin B inactivates CRM1/exportin 1 by covalent modification at a cysteine residue in the central conserved region. Proc Natl
Acad Sci USA 96: 9112-9117 (1999)

7. Fukuda M, Asano S, Nakamura T, Adachi M, Yoshida M, Yanagida M, Nishida E. CRM1 is responsible for intracellular transport mediated by the nuclear export signal. Nature 390: 308-311 (1997)

8. Fornerod M, Ohno M, Yoshida M, Mattaj IW. CRM1 is an export receptor for leucine-rich nuclear export signals. Cell 90: 1051-1060 (1997)

9. Rogalla T, Ehrnsperger M, Preville X, Kotlyarov A, Lutsch G, Ducasse C, Paul C, Wieske M, Arrigo AP, Buchner J, Gaestel M. Regulation of Hsp27 oligomerization, chaperone function, and protective activity against oxidative stress/tumor necrosis factor alpha by phosphorylation. J Biol Chem 274: 18947-18956 (1999)

10. Artal-Sanz M, Tsang WY, Willems EM, Grivell LA, Lemire BD, van der Spek H, Nijtmans LG. The mitochondrial prohibitin complex is essential for embryonic viability and germline function in Caenorhabditis elegans. J Biol Chem 278: 32091-32099 (2003)

11. Wang S, Nath N, Fusaro G, Chellappan S. Rb and prohibitin target distinct regions of E2F1 for repression and respond to different upstream signals. Mol Cell Biol 19: 7447-7460 (1999)

12. Fusaro G, Dasgupta P, Rastogi S, Joshi B, Chellappan S. Prohibitin induces the transcriptional activity of p53 and is exported from the nucleus upon apoptotic signaling. J Biol Chem 278: 47853-47861 (2003)

13. Mishra S, Murphy LC, Nyomba BL, Murphy LJ. Prohibitin: a potential target for new therapeutics. Trends Mol Med 11: 192-197 (2005)

14. Coates PJ, Jamieson DJ, Smart K, Prescott AR, Hall PA. The prohibitin family of mitochondrial proteins regulate replicative lifespan. Curr Biol 7: 607-610 (1997)

15. Gamble SC, Odontiadis M, Waxman J, Westbrook JA, Dunn MJ, Wait R, Lam EW, Bevan CL. Androgens target prohibitin to regulate proliferation of prostate cancer cells. Oncogene 23: 2996-3004 (2004)

16. Fusaro G, Wang S, Chellappan S. Differential regulation of $\mathrm{Rb}$ family proteins and prohibitin during camptothecininduced apoptosis. Oncogene 21: 4539-4548 (2002)

17. Arrigo AP. Small stress proteins: chaperones that act as regulators of intracellular redox state and programmed cell death. Biol Chem 379: 19-26 (1998)

18. Reed JC. Cytochrome c: can't live with it-can't live without it. Cell 91: 559-562 (1997)

19. Mehle P, Hickey E, Weber LA, Arrigo AP. Large unphosphorylated aggregates as the active form of hsp27 which controls intracellular reactive oxygen species and glutathione levels and generates a protection against TNFalpha in NIH-3T3-ras cells. Biochem Biophys Res Commun 241: 187-192 (1997)

20. Garrido C, Bruey JM, Fromentin A, Hammann A, Arrigo AP, Solary E. HSP27 inhibits cytochrome c-dependent activation of procaspase-9. Faseb J 13: 2061-2070 (1999)

21. Bruey JM, Ducasse C, Bonniaud P, Ravagnan L, Susin SA, 
Diaz-Latoud C, Gurbuxani S, Arrigo AP, Kroemer G, Solary E, Garrido C. Hsp27 negatively regulates cell death by interacting with cytochrome c. Nat Cell Biol 2: 645-652 (2000)

22. Pandey P, Farber R, Nakazawa A, Kumar S, Bharti A, Nalin C, Weichselbaum R, Kufe D, Kharbanda S. Hsp27 functions as a negative regulator of cytochrome c-dependent activation of procaspase-3. Oncogene 19: 1975-1981 (2000)

23. Paul C, Manero F, Gonin S, Kretz-Remy C, Virot S, Arrigo AP. Hsp27 as a negative regulator of cytochrome $\mathrm{C}$ release. Mol Cell Biol 22: 816-834 (2002) 